\title{
Lethal and temperature-sensitive mutations and their suppressors identify an essential structural element in U2 small nuclear RNA
}

\author{
Manuel Ares, Jr. and A. Haller Igel \\ Biology Department, University of California at Santa Cruz, Santa Cruz, California 95064 USA
}

\begin{abstract}
U2 snRNA is an essential component of the splicing apparatus in eukaryotic cells. Three possible secondary structures for the highly conserved $5^{\prime}$ half of U2 snRNA are consistent with U2 phylogenetic sequence variation. To distinguish among these models and to test the function of U2 structural elements, we made $>35$ mutations in the yeast U2 snRNA gene. Some of the mutations were designed in pairs so that combinations could be made that would restore base-pairing to differentiate helix requirements from primary sequence requirements. The mutations identify an essential stem-and-loop structure adjacent to the branchpoint interaction region. A conserved complementarity to the loop just upstream of the $\mathrm{Sm}$ site and an additional conserved stem-loop are dispensable for $\mathrm{U} 2$ function, even in the background of a previously identified large internal deletion. Non-Watson-Crick base appositions at the 53-62 base pair in the essential stem lead to a variety of temperature and $\mathrm{KCl}$-sensitive phenotypes, as well as an accumulation of unspliced precursors in vivo. Chemical structure probing of U2 RNA in vivo reveals that the bulk of $U 2$ in a yeast cell adopts a structure in good agreement with that deduced from genetic results. We suggest that this stem-loop is not a binding site for an intrinsic U2 snRNP protein but may interact with other factors during spliceosome assembly or splicing.
\end{abstract}

[Key Words: U2 snRNA; eukaryotic cells; splicing apparatus; stem-loop structure]

Received August 14, 1990; revised version accepted September 24, 1990.

U2 small nuclear RNA (snRNA) is one of five conserved RNA molecules involved in splicing pre-mRNA. The U1, U2, U4, U5, and U6 snRNAs are assembled with proteins into four small nuclear ribonucleoprotein (snRNP) particles (the U1, U2, U4 + U6, and the U5 snRNP|, which associate specifically with pre-mRNA and with each other to form the spliceosome, the macromolecular complex where splicing occurs /see Steitz et al. 1988; Woolford 1989). At an early stage in spliceosome assembly, the U2 snRNP becomes associated with the region of pre-mRNA destined to be the branchpoint (Black et al. 1985; Konarska and Sharp 1986; Bindereif and Green 1987; Chabot and Steitz 1987; Kramer 1987).

Recognition of the branchpoint is a complex process that may vary in different species. In yeast, branch formation requires neither a 3 '-splice site nor a polypyrimidine-rich sequence, and the branch always occurs at the sixth position of a conserved sequence UACUAAC (for review, see Woolford 1989). Order of addition experiments with $\mathrm{U} 1$ and $\mathrm{U} 2$ depleted yeast splicing extracts, and studies assessing the impact of branchpoint mutations on splicing have identified a requirement for the UACUAAC sequence for stable Ul binding to the premRNA in the absence of U2 (Legrain et al. 1988; Ruby and Abelson 1988; Seraphin and Rosbash 1989|, suggesting that a factor other than the $\mathrm{U} 2$ snRNP recognizes the branchpoint in advance of U2. The U2 snRNP interacts with the branchpoint sequence during splicing through U2 RNA-pre-mRNA base-pairing, and this interaction is essential for efficient splicing in yeast (Parker et al. 1987).

Mammalian introns rely on a polypyrimidine signal to bind the U2 snRNP (Konarska and Sharp 1986; Bindereif and Green 1987; Chabot and Steitz 1987; Kramer 1987; Ruskin et al. 1988|. Unlike yeast, U2 snRNP binding can occur in vitro independently of the presence of $5^{\prime}$-splice site sequences (Konarska and Sharp 1986; Bindereif and Green 1987; Chabot and Steitz 1987; Kramer 1987; Ruskin et al. 1988) and is dependent on protein factors sensitive to the polypyrimidine tract in pre-mRNA for efficient binding (Ruskin et al. 1988 Garcia-Blanco et al. 1989; Kramer 1989; Zamore and Green 1989|. Although first recognized just upstream of the $3^{\prime}$-splice site (Mount 1982), recent evidence indicates that the polypyrimidine tract may more properly be thought of as associated with the branchpoint (Smith et al. 1989). Extensive complementarity between U2 RNA and the branchpoint is not essential for mammalian splicing because 
cryptic branchpoints are easily recruited when wild-type branchpoints are removed (see Green 1986), and it is difficult to identify convincing U2-branchpoint complementarity at some metazoan branchpoints (Hartmuth and Barta 1988). However, improvement of match to UACUAAC of a mammalian branchpoint improves the efficiency of its use (Reed and Maniatis 1988; Zhuang et al. 1989), perhaps because of an intrinsic sequence-specific binding activity of the U2 snRNP /Nelson and Green 1989). As in yeast, compensatory mutations in the branchpoint recognition region of human U2 improve the use of altered branchpoints (Wu and Manley 1989; Zhuang and Weiner 1989). It remains to be seen whether differences in branchpoint recognition between yeast and metazoans involve only the relative contributions of sequence-specific U2 binding versus accessory factors or whether there is a more fundamental difference.

In trypanosomes and nematodes, a trans-splicing process mechanistically similar to cis-splicing takes place where a $5^{\prime}$ exon is donated by an snRNA-like molecule to the body of an mRNA, which in the case of nematodes, can also undergo cis-splicing (for reviews, see Laird 1989; Nilsen 1989|. Trans-splicing in trypanosomes requires intact U2 snRNA (Tschudi and Ullu 1990), but trypanosome U2 is highly divergent from yeast and metazoan U2 in the region that base-pairs to the pre-mRNA (Tschudi et al. 1986, 1990; Mottram et al. 1989|. Five trypanosome branchpoints have been mapped, and none contain clear complementarity to this region of trypanosome U2 (Patzelt et al. 1989). Of two nematode branchpoints mapped, one contains good complementarity to nematode U2, (which is not divergent from mammalian U2 (Thomas et al. 1990), and one does not (Hannon et al. 1990). In branchpoint sequence conservation and requirements for strong U2 complementarity, branchpoint selection during trans-splicing seems more similar to metazoan splicing than to yeast and will probably rely more on accessory factors than base-pairing.

In spite of the apparent differences in branchpoint recognition, the primary sequences of the first 110-120 nucleotides of U2 RNA are highly conserved among yeast, mammals, and trypanosomes. Extra sequences found in yeast but not metazoan U2 are not essential for splicing because deletion derivatives of yeast U2 lacking the extra sequences function in vivo (Igel and Ares 1988; Shuster and Guthrie 1988). In addition, derivatives of human $U 2$ can functionally replace yeast $U 2$ in vivo (Shuster and Guthrie 1990; S. Seiwert and M. Ares, unpubl.), suggesting that little of the phylogenetic variation in U2 sequence between metazoans and yeast has much relevance to the mechanism of U2 action. Analysis of the pattern of nucleotide substitutions in the highly conserved first 110-120 nucleotides of U2 from different organisms has led to the identification of several pairs of short stretches of sequence which, although variable in primary sequence, remain complementary by compensatory covariation and may represent RNA duplex (Guthrie and Patterson 1988; Ares and Igel 1989).
Unfortunately, current phylogenetic data do not distinguish among three possible structures for the conserved region of U2.

The mechanism by which factors stimulate U2 snRNP binding to pre-mRNA is unknown. Structural domains of U2 RNA or the U2 snRNP required for catalysis or interaction with auxiliary factors during spliceosome assembly or splicing have not been identified. To test structure models and to determine the importance of U2 structural elements to the role of U2 in splicing, we have constructed and tested $>35$ mutations of the yeast U2 gene. Surprisingly, of the three conserved phylogenetically supported helices we tested, only one is essential for U2 function. The loop formed by this helix has a conserved primary sequence and an essential function. This is the only indispensable stem-loop structure identified so far in U2 snRNA.

\section{Results}

Three possible secondary structures are consistent with phylogenetic data

The analysis of phylogenetic variation in U2 sequence has suggested the presence of three helices in the region from nucleotide 48 to 105 (Fig. 1; see Guthrie and Patterson 1988; Ares and Igel 1989). Two of the helices formed by pairing $\mathrm{A}$ (nucleotides $48-53$ ) with $\mathrm{A}^{\prime}$ (nucleotides 62-67) and B (nucleotides 54-61) with $\mathrm{B}^{\prime}$ (nucleotides 98-105) would form a pseudoknot (Pleij et al. 1985) if they existed simultaneously (Fig. 1b), whereas the $\mathrm{C}^{-} \mathrm{C}^{\prime}$. helix (nucleotides $68-74$ paired to $78-83$ ) would lie outside. Two unpseudoknotted structures are consistent with phylogenetic data, one proposed by Keller and Noon (1985; Fig. 2a) consisting of the C-C and the B-B' helices, and the other (Fig. 1c) consisting of only the A-A' and the $\mathrm{C}-\mathrm{C}^{\prime}$ helix. Phylogenetic data will superimpose all conserved helices, so that in cases where conformational change occurs, more than one of the proposed structures may be important. Phylogenetic comparisons alone cannot distinguish which of the three secondary structures is functionally relevant.

Using site-directed mutagenesis, we constructed U2 mutations designed to disrupt potential helices to test the models and eliminate one or more from consideration. Mutations were made singly and in pairs, designed such that the combination of the two would restore complementarity using different primary sequences. Additional mutations were made to delete structural domains that appeared to tolerate multiplebase substitutions. The mutant U2 genes were tested by a plasmid shuffling technique (Fig. ld) on the basis of the observation that yeast cells that become lys2- can be selected on medium containing $\alpha$-aminoadipate $(\alpha-\mathrm{AA})$ as the primary nitrogen source (Chattoo et al. 1979). We constructed a yeast strain with a lethal deletion of the chromosomal U2 gene and a centromere plasmid carrying the wild-type U2 gene and the LYS2 gene (Barnes and Thorner 1986). Cells lacking the U2, LYS2 plasmid arise spontaneously at a frequency of $\sim 1-5 \%$ per cell 

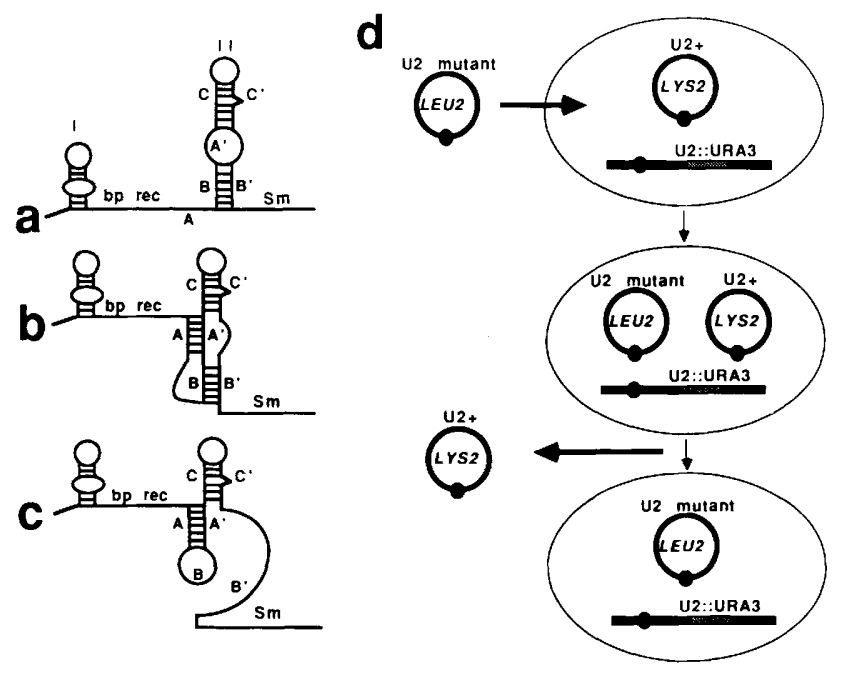

Figure 1. Three phylogenetically supported secondary structure models and the genetic scheme used to test them. $\{a\}$ Open structure with A-A' unpaired first proposed by Keller and Noon (1985); (b) pseudoknotted structure with all phylogenetically supported complementarities paired; $(c)$ alternative structure with B-B' unpaired; (d) genetic scheme for testing U2 mutations for function. A strain carrying a lethal chromosomal U2 disnuption and a wild-type or marked (pseudo-wild-type) U2 gene on a LYS2 centromere plasmid is transformed to leucine independence with a LEU2 plasmid carrying the mutant $U 2$ gene to be tested. Any dominant effects of the mutation would be apparent immediately. To test the mutant $\mathrm{U} 2$ for function and to reveal any recessive phenotypes associated with the $U 2$ mutation, cells are replica-plated to medium containing $\alpha$-AA as the primary nitrogen source to select for cells that have lost the LYS2 plasmid containing the wild-type U2 gene. Such cells arise spontaneously and can grow on this medium only if the mutant $U 2$ on the LEU2 plasmid is functional.

generation, and such cells can grow on $\alpha$-AA only if they contain a functional U2 gene on a second plasmid. Derivatives of this strain were constructed containing the different $\mathrm{U} 2$ mutations on a second centromere plasmid and were replicated to $\alpha$-AA medium. Failure of such strains to give rise to viable lys2- mitotic segregants is taken as an indication that the U2 mutation on the second plasmid is lethal, whereas efficient growth after replicating to $\alpha-\mathrm{AA}$ indicates that the mutation is not lethal.

\section{A lethal mutation in $A$ can be suppressed by $a$ compensatory mutation in $A^{\prime}$ that is itself lethal}

To test the requirement for complementarity between nucleotides 48-54 (A) and 61-67 (A') we made two triple mutations that disrupt this complementarity, one in A and one in A' (Fig. 2a), as well as the "double" (sextuple) mutation smA, which is a combination of $\operatorname{tmA}$ and $\operatorname{tmA} A^{\prime}$, and which restores the complementarity. Figure $2 \mathrm{~b}$ shows that plasmid shuffling results from these and other U2 mutations. Cells containing the wild-type U2, LEU2 plasmid grow efficiently after shuffling (Fig. 2b, spot A2), whereas cells containing the same plasmid deleted of the U2 promoter and $5^{\prime}$ half of the gene do not (spot A1). The mutations that disrupt the A- $\mathrm{A}^{\prime}$ complementarity tmA (spot B1) or tmA' (spot $B 2$ ) are unable to grow after loss of the wild-type U2 gene on $\alpha$-AA, whereas the compensatory sextuple mutation, which restores complementarity using a different primary sequence, is able to grow (Fig. 2b, spot B3).

To eliminate the possibility that failure to function was due to poor synthesis or stability of the mutant RNA, we performed primer extension on RNA from the strains before shuffling. These strains contain two U2 genes: a pseudo-wild-type gene containing a mutation of C121 to U on a LYS2 plasmid, and the mutant U2 being tested, which carries the natural $\mathrm{C}$ residue at position 121 , on a LEU2 plasmid. We monitored the relative amounts of the two U2 RNAs in these cells by primer extension using dideoxy-ATP in place of dATP (Fig. 2c). A primer $(23 \mathrm{~T})$ annealed to the pseudo-wild-type RNA can only be extended under these conditions to the altered $U$ at position 121, whereas primer annealed to the mutant RNA can be extended to the next $U$ in the template at position 118. The C121U mutation in the pseudo-wild-type gene is viable (Fig. 2b, spot A3) and has a mild effect on the steady-state level of U2 when present in cells with a true wild-type gene, because it is not accumulated to the same extent as wild-type U2 in these cells (Fig. 2c, lane 3). We know that this effect is not due to the plasmid construct, because a strain carrying the wild-type U2 on the LYS2 plasmid and the C121U pseudo-wild-type U2 on the LEU2 plasmid produces the same relative amounts of wild-type and pseudo-wild-type U2 RNA as that shown in Figure 2b, lane 3 (data not shown).

The mutations tmA and tmA', which disrupt stem $\mathrm{A}$, do not cause $U 2$ to fail to accumulate to a lesser extent than other functional versions of U2 (Fig. 2c, lanes 4 and 5 ), eliminating poor synthesis or accumulation of the mutant RNA as an explanation for lack of function. We conclude that consequences of disruption of stem $\mathrm{A}$ or the formation of aberrant alternate U2 secondary structures are the reasons for the failure of these mutants to function. Restoration of stem A with a different primary sequence or prevention of alternate foldings due to restored complementarity in the smA mutant is consistent with function, suggesting that stem $A$ is essential for U2 function.

\section{The phylogenetically conserved complementarity between loop $B$ and $B^{\prime}$ is dispensable}

A similar set of triple mutations was constructed in the B-B' complementarity (Fig. 2a), with very different results. Neither triple mutation $\mathrm{tmB}$ (Fig. 2b, spot C1) nor $\mathrm{tmB}^{\prime}$ (spot $\mathrm{C} 2$ ) is lethal or has any discernible temperature-sensitive phenotype (data not shown), whereas the sextuple mutation $\mathrm{smB}$ is viable but is heat and cold sensitive (spot C3 and data not shown). Because of the potential for residual complementarity in the tmB and tmB' mutations, we made quintuple mutations $\mathrm{qmB}$ and $\mathrm{qmB}^{\prime}$, and the compensatory dectuple $\mathrm{dmB}$. The $\mathrm{qmB}$ 

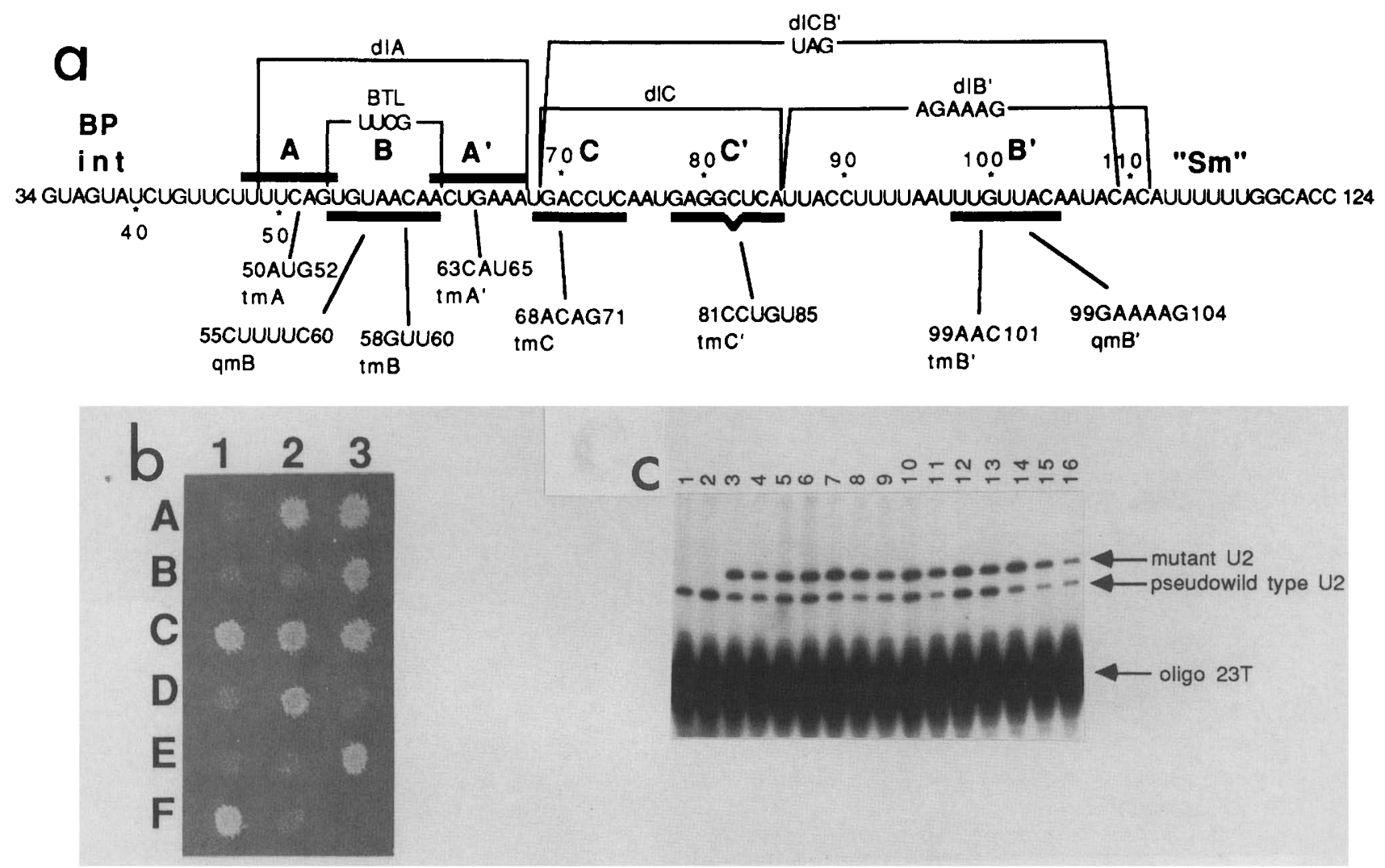

Figure 2. U2 mutations to test requirement of phylogenetically conserved complementarities. (a) Sequence of yeast U2 between positions 34 and 124. Phylogenetically conserved complementarities $A-A^{\prime}, B-B^{\prime}$, and $C-C^{\prime}$ are indicated by bars. The Sm site and the branchpoint interaction region are indicated. Sequence changes in the different mutations are indicated below the sequence. The changed sequence is written and represents the new sequence at the positions indicated. Deletion mutations BTL, dlB', dlC, dlCB', and dlA lack the sequences spanned by the brackets; and where nucleotides are added, the sequence is shown as part of the bracket. Not shown are smA, which is a double (sextuple) mutant $\operatorname{tmA}$ plus $\operatorname{tmA}^{\prime}$; $\operatorname{smB}$, a double (sextuple) mutant $\operatorname{tmB}$ and $\operatorname{tmB}$; $d \mathrm{mB}$, a double (dectuple) mutant qmB plus $\mathrm{qmB}^{\prime}$. $(b)$ Growth of cells containing only the mutant U2. Strains derived by introduction of mutant U2 into the strain carrying the LYS2-U2 plasmid (see Fig. 1) were spotted on complete medium lacking lysine and leucine. After growth, the spots were replicated to a plate containing $\alpha-\mathrm{AA}$, incubated at $30^{\circ} \mathrm{C}$ for 3 days, and photographed. $\mathrm{U} 2$ plasmids tested are located as follows: (A1) 3' half of gene; $(\mathrm{A} 2)$ wild type; (A3) C121U; $(\mathrm{B} 1) \mathrm{tmA} ;(\mathrm{B} 2) \mathrm{tmA}^{\prime} ;(\mathrm{B} 3) \mathrm{smA} ;(\mathrm{C} 1) \mathrm{tmB} ;(\mathrm{C} 2) \mathrm{tmB}$; (C3) smB; (D1) qmB; (D2) qmB'; (D3) dmB; (E1) BTL; (E2) dlA; (E3) dlB'; (F1) dlC; (F2) dlCB' . (c) Accumulation of mutant U2 RNAs. End-labeled primer $23 \mathrm{~T}$ was annealed to RNA from strain HI70 derivatives carrying different U2-LEU2 plasmids and extended with reverse transcriptase, dGTP, dCTP, dTTP, and ddATP in place of dATP. HI70 carries a pseudo-wild-type U2 gene with C121 changed to U. The $3^{\prime}$ of primer $23 \mathrm{~T}$ is complementary to U130, and there are no other U residues in the template until position 121 in the pseudowild-type $U 2$, giving rise to the shorter extension product, or position 118 in the mutant $U 2$, giving rise to the longer primer extension product (see arrows). Samples are $3^{\prime}$ half of the gene (lane 1); C121U (lane 2); wild type (lane 3); tmA (lane 4); tmA' (lane 5); smA (lane 6); $\mathrm{tmB}$ (lane 7); $\mathrm{tmB}^{\prime}$ (lane 8); $\mathrm{smB}$ (lane 9); qmB (lane 10); qmB' (lane 11); dmB (lane 12); BTL (lane 13); diB' (lane 14); dlC (lane 15); dlCB' (lane 16).

mutation is lethal (spot D1), whereas qmB' is not (spot D2). Support for the importance of this complementarity might have come if qmB' could suppress the lethal effect of $\mathrm{qmB}$, but this is not the case, as the compensatory dectuple mutation is also lethal (spot D3). These results suggested that loop B might be essential (or that the qmB mutation induces a lethal alternative folding of U2) and that the $B^{\prime}$ region is dispensable.

Two additional mutations were made to confirm these results and to test the idea that loop $B$ is essential. The first was a replacement of loop B with a tetraloop sequence. Tetraloops are 4-nucleotide loop sequences that increase the thermal stability of the helices that they top, probably by special self-interactions or stacking with the helix (Tuerk et al. 1988). Although other possibilities exist, we felt that a tetraloop would be least likely to induce alternative foldings that would disrupt stem A, a structure shown here to be important for U2 function. This mutation, BTL, has nucleotides 54-61 deleted and replaced with UUCG, forming the acceptable but not typical tetraloop GUUCGC (see Tuerk et al. 1988), and is lethal (Fig. 2b, spot E1). This suggests that some feature of loop B (primary sequence, secondary or tertiary structure, orientation relative to the end of the helix, or contribution to the stability of the helix) is essential for $\mathrm{U} 2$ function. A mutation $\mathrm{dlB}^{\prime}$, which replaces the $B^{\prime}$ sequence (as well as everything from the base of stem-loop $\mathrm{C}$ to the $\mathrm{Sm}$ site) with a short run of purines 
not obviously complementary to $B$, is not lethal (spot E3), confirming that $\mathrm{B}-\mathrm{B}^{\prime}$ complementarity is not essential for splicing. This mutation is slightly cold sensitive (data not shown). Primer extension reveals that for all mutations in the $\mathrm{B}$ and $\mathrm{B}^{\prime}$ regions, defective U2 RNA synthesis or stability, as reflected by the relative steadystate level of the mutant RNA, is not the explanation for the failure of the lethal mutations to function (Fig. 2c, lanes $7-14)$. We conclude that the U2 secondary structure model best reflecting that required for performance of essential U2 functions is shown in Figure lc.

\section{The phylogenetically conserved stem-loop $C$ is also dispensable for splicing}

The existence of stem-loop C is well supported by phylogenetic variation and is conserved in all U2 RNAs (Guthrie and Patterson 1988; Ares and Igel 1989). We made triple mutations tmC and $\mathrm{tmC}^{\prime}$ (Fig. 2a), both of which are viable, although $\mathrm{tmC}^{\prime}$ is slightly cold sensitive (data not shown). The cold-sensitive phenotype is suppressed in the compensatory double (sextuple) mutant smC and is not due to poor synthesis or accumulation of $\mathrm{U} 2$ (data not shown). More effective in demonstrating the dispensable nature of this element is the complete deletion of stem-loop $\mathrm{C}, \mathrm{dlC}$, which is neither lethal (Fig. 2b, spot F1) nor temperature sensitive (data not shown). Because tmC suppresses the cold-sensitive phenotype of $\mathrm{tmC}^{\prime}$, we conclude that $\mathrm{C}$ and $\mathrm{C}^{\prime}$ base-pair with each other; however, the structure formed by this interaction, stem-loop $\mathrm{C}$, is not essential for splicing or growth at high or low temperature.

Deletion of both stem-loop C and the $\mathrm{B}^{\prime}$ region as in mutant dlCB', does not result in a functional U2 (Fig. $2 b$, spot F2), even though the RNA is synthesized and accumulated efficiently (Fig. 2c, lane 16) and each element can be deleted independently without lethality (Fig. 2b, spots E3 and F1). This may mean that either the two regions are functionally equivalent and redundant although structurally dissimilar, which seems unlikely, or that each single mutation is slightly affected and the additive or synergistic effect of the combination reduces U2 function to below a necessary threshold for viability. Another possibility is that the particular juxtaposition of sequences in the double deletion creates an alternative RNA structure inconsistent with function.

\section{Functional equivalents of stem-loop $C$ or $B^{\prime}$ are not} found in the internal dispensable U2 sequences

All mutations described so far have been made in an otherwise wild-type copy of the U2 gene. Previously, we have shown that U2 sequences from positions 123 to 1081 are dispensable for splicing (Igel and Ares 1988; see also Shuster and Guthrie 1988). Although we considered it unlikely, we wanted to test the possibility that functional equivalents of stem-loop C and B' might reside in the region between positions 123 and 1081 . To do this, we introduced the $\mathrm{dlC}$, $\mathrm{dlB}^{\prime}$, and $\mathrm{dlCB}^{\prime}$ mutations into the U2 minigene lacking sequences between 123 and 1081 (dlBD; Igel and Ares 1988) and tested them by plasmid shuffling. Cells containing only the wild-type minigene dlBD are viable (Fig. 3a, spot A1; Igel and Ares 1988), as are those containing the mini-dlC (spot B1) or mini-dlB' (spot B2). As with the full-length U2, the mini-dlCB' U2 is lethal (spot B3). A blot of RNA from strains grown after shuffling out the full-length wildtype U2 plasmid shows that the cells contain only the appropriate mini-U2 RNAs (Fig. 3b, lanes 4, 5). The mini-dlCB' transcript accumulates well (lane 6), indicating that it fails to function for a reason other than poor accumulation. We conclude that the dispensable nature of the stem-loop C and the B' sequence element observed in the background of the full-length gene is not due to functional reiteration of these elements between positions 123 and 1081 .

An experiment to add to the mini-U2 RNA a stemloop found in yeast U2 at positions $633-650$ that is structurally equivalent to stem-loop III of metazoan U2 (Ares and Igel 1989; B. Seraphin, pers. comm.), is also presented here. Addition of the stem-loop does not disrupt function (Fig. 3a, spot A2) but also does not correct the altered $3^{\prime}$-end formation or poor accumulation of the internally deleted transcript relative to wild type that we reported previously for the dlBD gene (Fig. 3b, lane 3; Igel and Ares 1988 and data not shown).

\section{Single-base changes in the highly conserved primary sequence of loop B have little effect on cell viability}

Inspection of the loop B sequence from a variety of organisms reveals a conserved primary sequence with the consensus NG/UUAAPyNN (Fig. 4a), which is represented in yeast by the sequence UGUAACAA. As shown above, the triple mutation tmB changes this to UGUAGUUA without effect on viability, whereas $\mathrm{qmB}$ changes it to UCUUUUCA and BTL deletes it and replaces it with UUCG, producing lethal phenotypes. To test the importance of this conserved loop sequence, we altered two phylogenetically invariant nucleotides, U56 and $A 57$, changing each to $C$ or $G$ (Fig. $4 \mathrm{~b}$ ). A phylogenetically consistent change $\mathrm{C} 59$ to $\mathrm{U}$ was also constructed. All the mutants are viable (Fig. 4c), and although U56C slightly reduces the steady-state level of U2 RNA (Fig. 4d), no temperature-sensitive phenotype is evident in any of the single-base changes in the loop (data not shown). We conclude that some structural feature of the loop B is essential for U2 function but that the phylogenetically conserved primary sequence found in the loop is not essential for splicing.

\section{Non-Watson-Crick base appositions at the G53-C62 base pair have growth phenotypes consistent in severity with expected severity of helical disruption}

To provide evidence against the possibility that stem A is not really essential itself, but that the tmA and tmA ${ }^{\prime}$ mutations are lethal because they sponsor the formation of alternate RNA structures that occlude adjacent essen- 


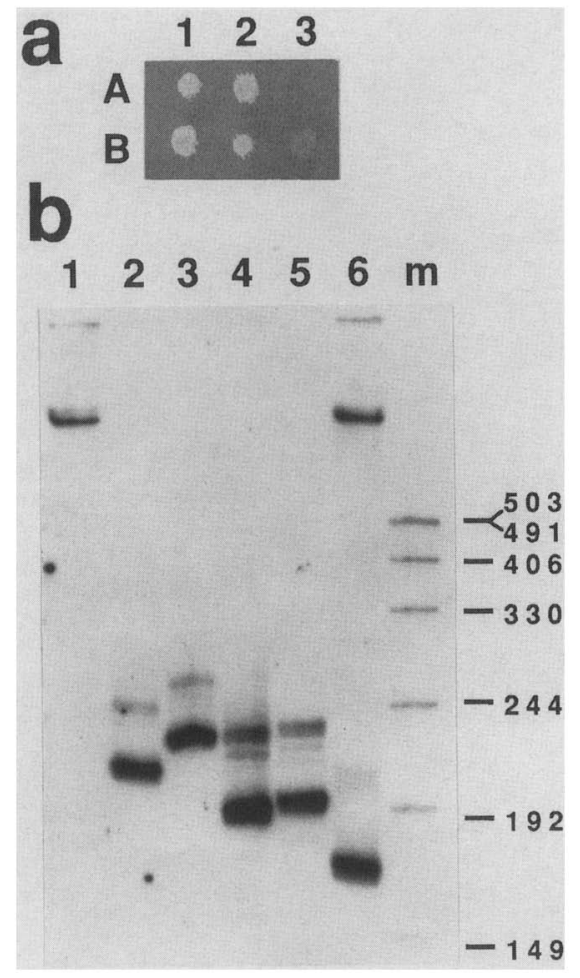

Figure 3. Conserved elements are dispensable in the mini-U2 background. $(a)$ Functional test of mini-U2 genes lacking different conserved elements. HI70 carrying mutant U2 plasmids were spotted and replicated to $\alpha$-AA medium as in the legend to Fig. 2(b). Strains are placed as follows: (A1) dlBD; $(\mathrm{A} 2)$ dlBD + III; $\langle\mathrm{B} 1\rangle$ dlBD-dlC; (B2) dlBD-dlB'; $\langle\mathrm{B} 3\}$ dlBD-dlCB'. (b) RNA from shuffled HI70 carrying only the mutant U2 plasmid (lanes 1-5) or from HI70 that carries a nonfunctional $\mathrm{U} 2$ and cannot be shuffled (lane 6) was fractionated on a ureapolyacrylamide gel, blotted to nylon membrane, and probed with a U2 oligonucleotide. (Lane 1) Wild-type U2; (lane 2) dlBD; (lane 3) dlBD + III; (lane 4) dlBD - dlC; (lane 5) dlBD - dlB'; (lane 6) dlBD - dlCB'; (m) markers are filled-in HpaII fragments of pUCl3 (sizes in nucleotides are indicated).

tial structures, we made a series of single-base mutations in stem A, as well as a complete deletion of stemloop A (Fig. 4b). The rationale for the design of the former mutations was to find regions where the structure might be more or less sensitive to disruption and to generate a set of mutations graded with respect to their expected impact on the structure of the helix. We felt that if the severity of the phenotype could be correlated with the expected severity of helical disruption, an argument could be made against alternative folding. Because new complementarities forming aberrant lethal pairings could arise as a consequence of any mutation, severe phenotypes might result even from acceptable (WatsonCrick) appositions. Although this argument only excludes certain types of alternative folding scenarios, we find that severity of phenotype is correlated with expected severity of helical disruption at the 53-62 base pair (Fig. 5).

A complete deletion of stem-loop A-B-A' is lethal
(Fig. 2a,b, spot E2). Single-base changes U49A, A66U, and the double mutation U49A : A66U (see Fig. 4b) are viable (Fig. 4c, spots B1, B2, and B3) and have no temperature-sensitive phenotype (data not shown), indicating that U-U or A-A apposition at base pair 49-66 is not sufficient to disrupt function in vivo. A G-U apposition at base pair 50-65 generated by the single-base change A65G is also viable (spot A3) and not temperature sensitive (not shown). In contrast, all of the mutations we have made in the 53-62 base pair that result in nonWatson-Crick base appositions have growth-deficiency phenotypes. Changing C62 to G results in a G-G apposition and is lethal (spot C2), but this is not due to poor synthesis or accumulation of the mutant RNA (Fig. 4d, lane 7). Mutation $\mathrm{G} 53 \mathrm{C}$ resulting in a $\mathrm{C}$ - $\mathrm{C}$ apposition is viable when shuffled at $30^{\circ} \mathrm{C}$ (Fig. $4 \mathrm{C}$, spot Cl) but grows slowly at $30^{\circ} \mathrm{C}$ and not at all at 18 or $36^{\circ} \mathrm{C}$ (Fig. 5). G53A results in an A-C apposition and is viable (Fig. 3A, spot D1), but is cold sensitive, as well as sensitive to medium containing high salt, especially at $36^{\circ} \mathrm{C}$ (Fig. 5). C62U results in a G-U apposition and is viable (Fig. 4c, spot D2). Although commonly found in RNA helices, a G-U base pair at 53-62 of U2 is not sufficient to allow wildtype growth and produces a cold-sensitive phenotype (Fig. 5). Finally, both standard Watson-Crick base pairs we made using double mutations G53C : C62G producing a C-G apposition and G53A : C62U producing an A-U apposition are viable (Fig. 4c, spots C3 and D3) and have wild-type growth characteristics (Fig. 5). Accumulation of all the mutant U2 RNAs in the presence of the pseudo-wild-type gene is efficient enough that poor synthesis or accumulation of the mutant RNA cannot explain the phenotypes (Fig. 4d).

\section{U2 mutations cause accumulation of unspliced pre-U3} RNA in vivo

To determine whether the $U 2$ mutations affect splicing and to begin to correlate growth phenotype of the mutations with their effect on RNA processing, we examined splicing of pre-U3 RNA. Both yeast U3 genes SNR17A and SNR17B (Hughes et al. 1987) contain introns with nontypical branchpoint sequences (GACUAAC instead of UACUAAC; Myslinski et al. 1990), and it seemed possible that splicing of the U3 introns might be more sensitive to U2 mutations than other introns. An oligonucleotide complementary to a region common to U3A and U3B was labeled, annealed to RNA from the mutants, and extended with reverse transcriptase. Because the two U3 genes have different size introns we can detect accumulation of both pre-U3A and pre-U3B in the same reactions (Fig. 6). U3 is a relatively stable abundant RNA, so we did not expect to see a decrease in the amount of spliced U3 in the mutants (Fig. 6). We observe an increase in the levels of both pre-U3 RNA species in cells carrying the $\mathrm{U} 2$ mutations. The ratio of pre-U3 to U3 in mutants G53C, G53A, and C62U, all of which display conditional growth defects, is increased (Fig. 6, lanes 3, 5, and 6). The identification of the tran- 

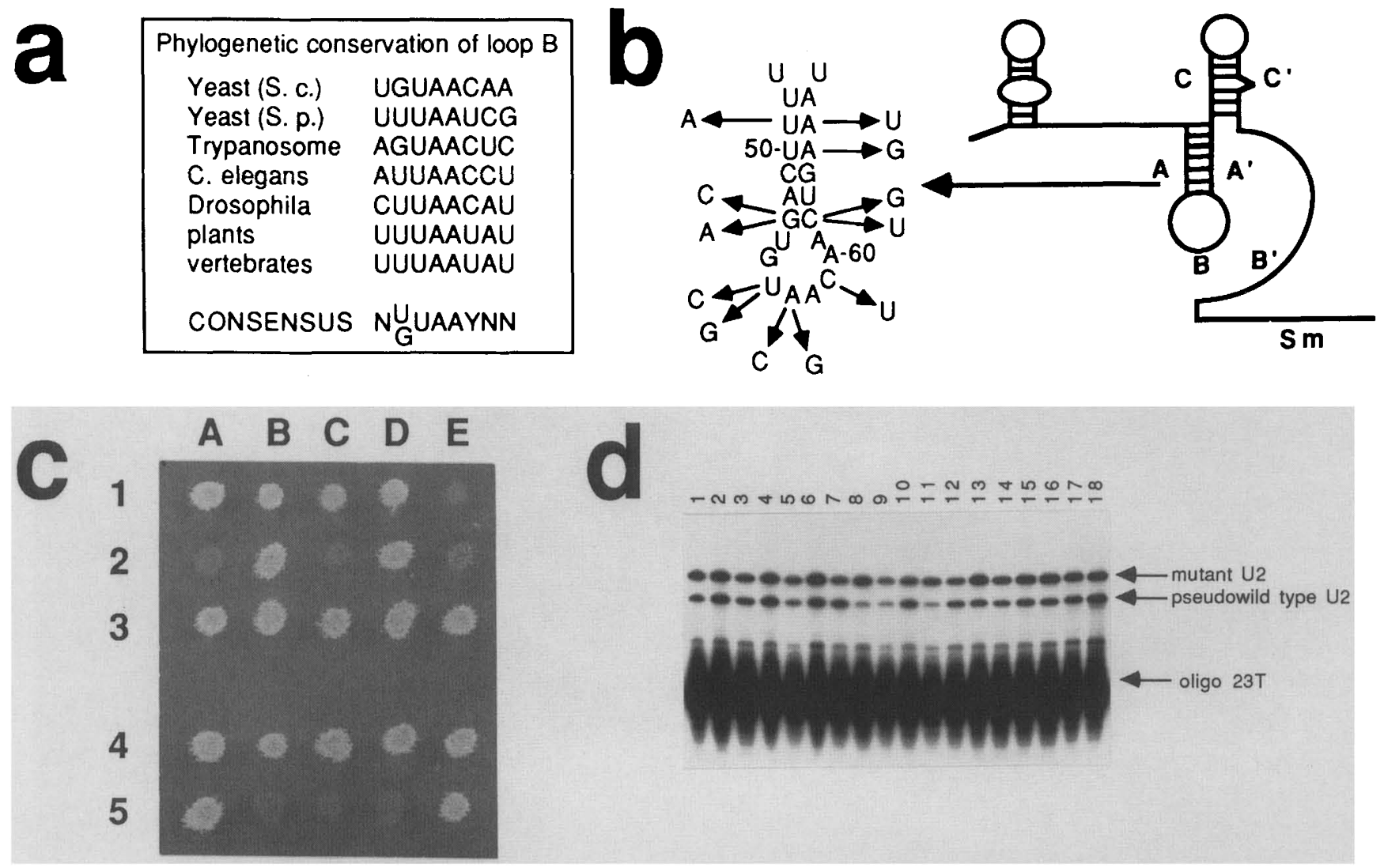

Figure 4. Function of mutations in the essential stem-loop. $(a)$ Consensus sequence derived by phylogenetic comparison of sequences in loop B (see Guthrie and Patterson 1988; Ares and Igel 1989). Note that in some organisms the nucleotides at the ends of the loop could form a Watson-Crick base pair, extending the helix and shortening (and possibly rotating) the loop. (b) Mutations in the essential stem-loop. The numbered yeast sequence is shown, and the changes are indicated. Not shown are the double mutants U49A : A66U, G53C : C62G, and G53A : C62U, the triple mutation tmB, the quintuple mutation qmB, and the tetraloop substitution BTL (see text and Fig. 2). (c) Plasmid shuffling of stem-loop mutations to test function. Cultures of HI70 transformed with various U2 plasmids were replicated to $\alpha-\mathrm{AA}$ as in Figs. $2 \mathrm{~b}$ and $3 \mathrm{a}$. Growth after 4 days at $30^{\circ} \mathrm{C}$ is shown. Strains contain the following $\mathrm{U} 2$ plasmids: (A1) Wild type; (A2) 3' half of the gene; (A3) A65G; (B1) U49A; (B2) A66U; (B3) U49A : A66U; (C1) G53C; (C2) C62G; (C3) G53C : C62G; (D1) G53A; (D2) C62U; (D3) G53A : C62U; (E1) tmA; (E2) tmA'; (E3) smA. (A4) U56C; (B4) U56G; (C4) A57G; (D4) A57C; (E4) C59U; (A5) tmB; (B5) qmB; (C5) BTL; (D5) 3' half of gene; (E5) wild type. (d) Accumulation of mutant U2 RNAs. RNA from $\mathrm{HI70}$ strains prior to shuffling was analyzed by primer extension as in Fig. 2c. Samples are wild type (lane 1); dlA (lane 2); tmA (lane 3); tmA' (lane 4); smA (lane 5); G53C (lane 6); C62G (lane 7); G53C : C62G (lane 8); G53A (lane 9); C62U (lane 10); G53A : C62U (lane 11); U56C (lane 12); U56G (lane 13); A57G (lane 14); A57C (lane 15); tmB (lane 16); qmB (lane 17); BTL (lane 18).

scripts is aided by the analysis of RNA from a prp4 strain, which carries a temperature-sensitive U4 snRNP protein (Banroques and Abelson 1989; Xu et al. 1990). Growth of this strain at permissive temperature shows low levels of the two pre-U3 species (lanel3), which increase after a 45 -min shift to restrictive temperature (lane 14). We have repeated these results more precisely by excising the U3 bands, measuring the amount of spliced U3 in the strains, and determining the amount of unspliced pre-U3 in RNA samples with identical amounts of spliced U3, with the same results as those in Figure 6. The ratio of pre-U3 to U3 observed in stem A mutants smA (lane 2), G53C: C62G (lane 4), and G53A : C62U (lane 7) is near wild-type levels, indicating that in addition to the the growth phenotype, suppression by compensatory double mutations extends to the splicing phenotype. Splicing of pre-U3 in loop B mutants (lanes 8-12) is similar to that of wild type (lane 1), consistent with their wild-type growth characteristics. We conclude that the mutations that disrupt U2 stem A structure reduce the efficiency of splicing and that this reduction in splicing contributes to the growth phenotype.

The effect of mutations on splicing of U3 is not correlated with the expected severity of helical disruption. For example, the effect of the cold-sensitive mutation $\mathrm{C} 62 \mathrm{U}$ (Fig. 6, lane 6) on U3 splicing is more severe than that of the barely viable mutant G53C (Fig. 6, lane 3). This raises the possibility that different mutations could be debilitated in different steps of splicing or could affect splicing of different transcripts differentially. Given different rates of turnover of spliced and unspliced transcripts of different types and the number of essential genes with introns in yeast, the relationship between inhibition of splicing by a U2 mutation and the effect on cell growth is likely to be extremely complex. 


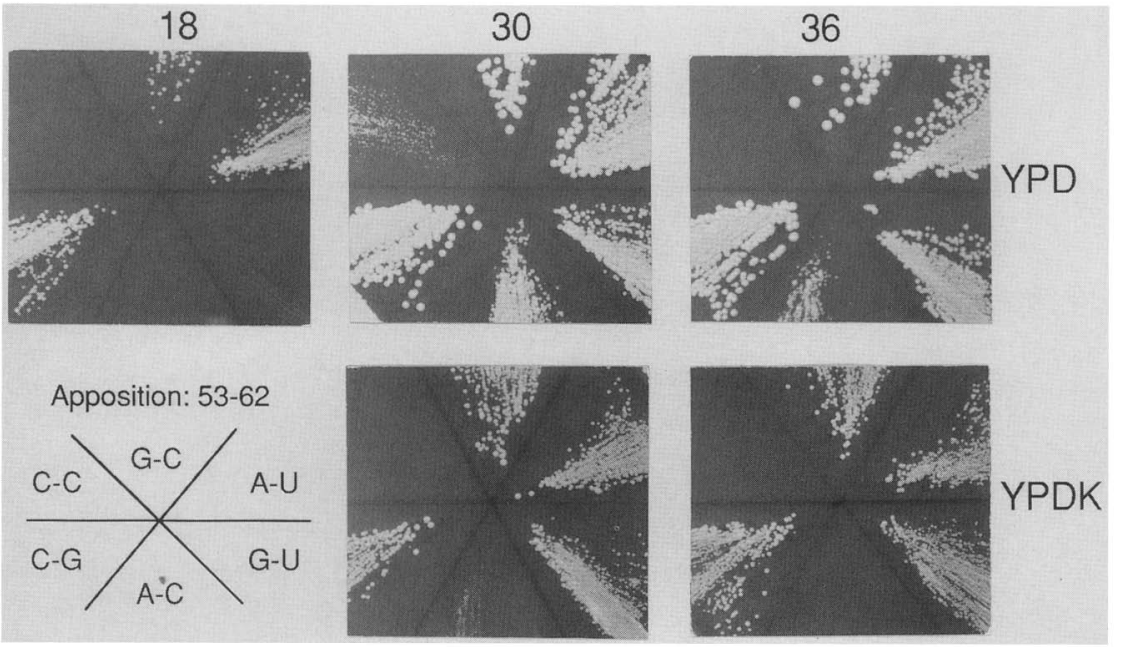

Figure 5. Colony formation by strains containing U2 mutations under different conditions. Cells were streaked on YPD (top) or YPD plus $1 \mathrm{M} \mathrm{KCl}$ (bottom) and incubated at $18^{\circ} \mathrm{C}($ left $), 30^{\circ} \mathrm{C}$ (center), or $36^{\circ} \mathrm{C}$ (right). Effect of mutations on base apposition at the 53-62 base pair and location of strains on the plate are indicated at lower left. Strains are located as follows: (Top) Wild type; (upper left) G53C; (lower left) G53C : C62G; (bottom) G53A; (lower rigini Co2U; (upper right) G53A : C62U. Plates were incubated for 3-5 days and photographed.

The bulk of U2 RNA in yeast cells adopts a secondary structure consistent with the impact of the mutations

To confirm that the functional picture of the secondary structure of $\mathrm{U} 2$ that emerges from the genetic analysis is

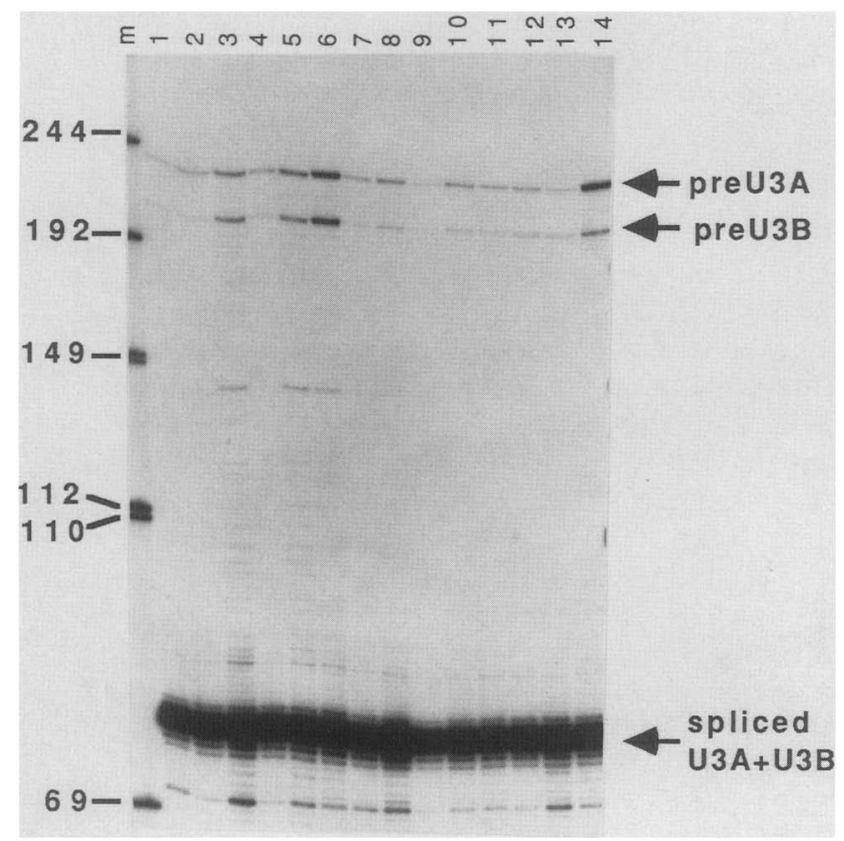

Figure 6. U2 mutations cause accumulation of pre-U3A and pre-U3B RNAs. Total RNA from different strains containing mutant U2 was isolated and primer-extended with an oligonucleotide probe complementary to a region common to both U3A and U3B. Because the U3A and U3B introns are different sizes (Myslinski et al. 1990), pre-U3A is longer than pre-U3B. Samples are wild type (lane 1); smA (lane 2); G53C (lane 3); G53C : C62G (lane 4); G53A (lane 5); C62U (lane 6); G53A : C62U (lane 7); U56C (lane 8); U56G (lane 9); A57G (lane 10); A57C (lane 11); tmB (lane 12). As a control, we measured pre-U3 levels in a temperature-sensitive prp4 mutant at permissive temperature $\left(23^{\circ} \mathrm{C}\right.$, lane 13$)$ and after $45 \mathrm{~min}$ at restrictive temperature $\left(36^{\circ} \mathrm{C}\right.$, lane 14). Arrows indicate the position of migration of U3-derived primer extension products. consistent with the actual conformation of U2, we probed the structure of $U 2$ in vivo using dimethylsulfate (DMS). DMS reacts with $\mathrm{N} 3$ of cytosine and N1 of adenine residues if they are not involved in base-pairing or other hydrogen bonds (Inoue and Cech 1985; Moazed et al. 1986). When modified RNA is used as a template for primer extension, $A$ and $C$ residues methylated at these positions cause strong stops to reverse transcriptase, allowing modified sites to be mapped (Inoue and Cech 1985; Moazed et al. 1986). We examined the accessibility of $A$ and $C$ residues in the $5^{\prime}$ domain of yeast $U 2$ as found in yeast cells (Fig. 7). Nucleotides A36, A39, and $\mathrm{C} 41$ in the branchpoint interaction region are accessible, consistent with the observed accessibility of this region of the U2 snRNP to oligonucleotides and RNase $\mathrm{H}$ in vitro (Black et al. 1985; Krainer and Maniatis 1985). Because A36 has been shown genetically to participate in a base-pairing interaction with the second U of UACUAAC (Parker et al. 1987), the accessibility of this nucleotide suggests that the bulk of U2 in vivo is not engaged in base-pairing to introns. Nucleotides C51 and $\mathrm{A} 52$ in the A region and A65, A66 and, to a lesser extent, A64 in the $A^{\prime}$ region are protected, consistent with the A- $\mathrm{A}^{\prime}$ base-pairing. Although we expect from phylogenetic (Guthrie and Patterson 1988; Ares and Igel 1989) and genetic (this work; Fig. 4) data that C62 and possibly A61 should be unreactive, they are partially reactive. This could be because of the tendency for the ends of helices to breathe or because the RNA may adopt other conformations part of the time, so that the reactivities of two or more pools of U2 in different conformational states are superimposed. It is also possible that some of the protections we observe are due to RNA-protein interactions, rather than base-pairing. Nucleotides in the $\mathrm{B}$ region $\mathrm{A} 57, \mathrm{~A} 58, \mathrm{C} 59$, and especially $\mathrm{A} 60$ are reactive consistent with these being part of a loop. Consistent with a lack of pairing of $B$ to $B^{\prime}$ is the accessibility of $B^{\prime}$ nucleotides A103, C104, and A105. The reactivity of nucleotides in $\mathrm{C}$ and $\mathrm{C}^{\prime}$ is consistent with stem-loop $\mathrm{C}$ in the model. In general, regions of U2 identified as stems by the genetic results are relatively protected 


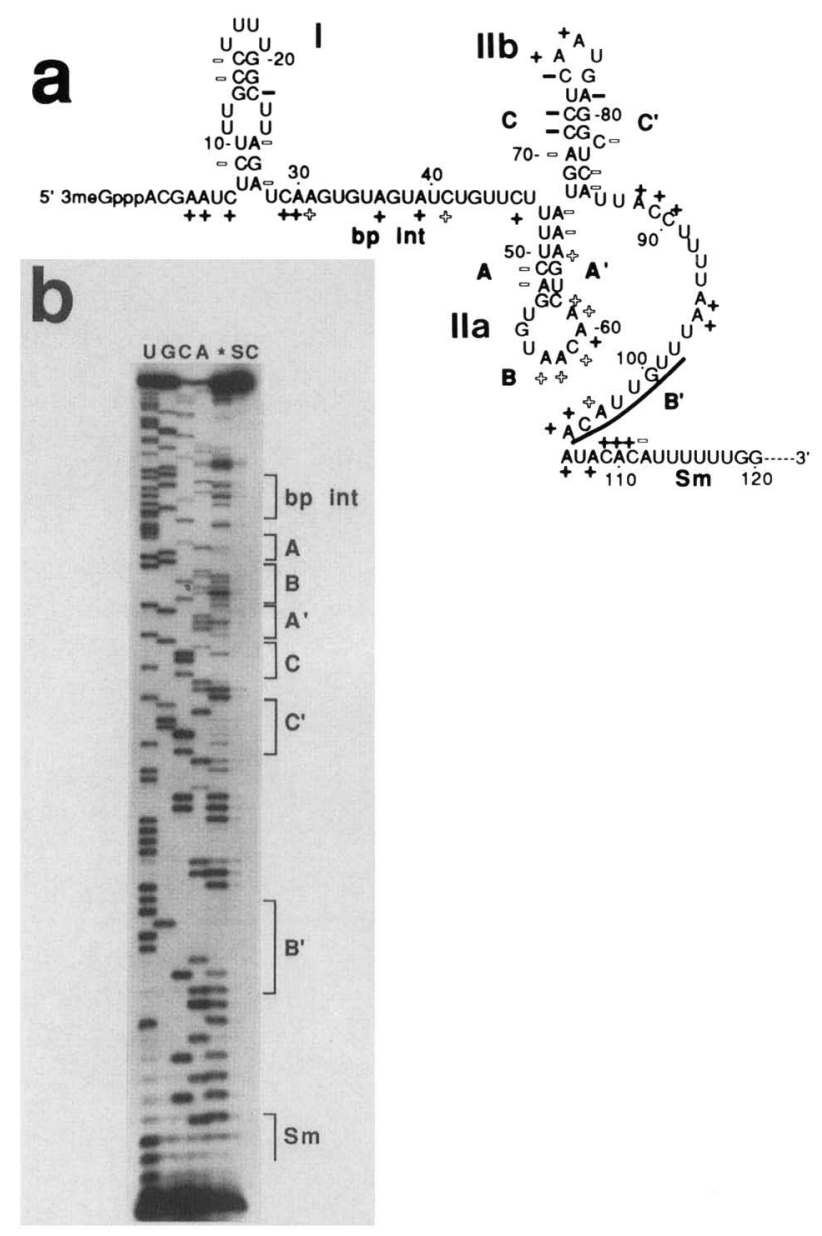

Figure 7. The secondary structure model is consistent with chemical probing of $U 2$ structure in vivo. (a) Sequence of the first 120 nucleotides of yeast U2 folded into the secondary structure model derived from genetic and phylogenetic considerations. Labeled are the branchpoint interaction region, the $\mathrm{Sm}$ site, and the phylogenetically conserved complementarities A-A', B-B', and C-C'. As stem-loop II of the Keller and Noon (1985) model is now broken into two stem-loops in this model, they are labeled IIa and IIb. Relative accessibility of U2 nucleotides to DMS in vivo is indicated as follows: (solid minus) Poor reactivity; (open minus) slight reactivity; (open plus) good reactivity; (solid plus) strong reactivity. (b) An in vivo structure probing experiment. Unmodified total RNA from wild type was used to generate a sequence derived from U2 RNA as a template. Reaction in lane $U$ contained ddATP; (lane $G$ ) ddCTP; (lane $C$ ) ddGTP; (lane $A$ ) ddTTP. The lane indicated by the asterisk $\left({ }^{*}\right)$ is RNA modified by DMS in vivo for $2 \mathrm{~min}$ at $30^{\circ} \mathrm{C}$ and then stopped. Lane $S C$ is a "stop control", where cells were exposed to DMS after the addition of the stop solutions to show that reactivities are not induced by the extraction procedure. Note that because dideoxynucleoside termination occurs with incorporation of the terminating nucleotide, the modified sites cause stops one nucleotide short of the corresponding dideoxy termination product.

from DMS modification, and those interpreted not to be required to pair for function are more reactive, demonstrating that the bulk of $\mathrm{U} 2$ in yeast cells adopts a conformation similar or identical to the functionally important conformation identified by the mutations.

\section{Discussion}

A single secondary structure model is supported by phylogenetics, genetics, and chemical probing

We have used site-directed mutagenesis to dissect the secondary structure of U2 snRNA. Of three possible structures predicted by phylogenetic data, two are eliminated in terms of essential function in splicing by the phenotypes of the mutations in the $\mathrm{B}^{\prime}$ sequence. The remaining structure model is supported by the demonstration of a requirement for stem $\mathrm{A}$ and the loop containing the B sequence. Structure probing of U2 snRNA in vivo confirms that the bulk of U2 snRNA is folded in a manner consistent with our interpretation of the impact of the mutations. A new feature of U2 structure not formerly appreciated is the stem A-A' and the loop B. The potential interaction between the $A$ and $A^{\prime}$ sequence was not supported by early phylogenetic comparisons because $\mathrm{A}$ and $\mathrm{A}^{\prime}$ are highly conserved in primary sequence. This structural element is essential for U2 function in vivo. To simplify the nomenclature of $\mathrm{U} 2$ structural elements we would suggest that the element formed by the A-A' pairing and loop B be called stemloop IIa, and the C-C' stem-loop be called stem-loop IIb, as indicated in Figure 7.

Only a very limited region of U2 snRNA is essential for splicing

Previous work on the structure and function of U2 snRNA has revealed that stem-loop I, stem-loop III, and stem-loop IV are not essential for splicing of at least certain pre-mRNA substrates. Yeast sequences containing a homolog of stem III (Ares and Igel 1989; B. Seraphin, pers. comm.) are dispensable for $\mathrm{U} 2$ function in vivo (Igel and Ares 1988; Shuster and Guthrie 1988). Stem-loop IV is also dispensable in yeast in vivo, but growth is affected (Shuster and Guthrie 1990). U2 RNAs lacking stem-loop III or stem-loop IV complement splicing in Xenopus oocytes depleted of functional U2 (Hamm et al. 1989; Pan and Prives 1989). A mutation tested by Hamm et al. (1989) lacking stem-loop I is also able to complement splicing of an adenovirus major late leader substrate injected into frog oocytes depleted of U2 snRNA; but in a similar assay using SV40 late premRNA, this deleted U2 did not appear to function (Pan and Prives 1989|. Although studies using oligonucleotide-directed RNase $\mathrm{H}$ cleavage of this region of $\mathrm{U} 2$ seemed to demonstrate a requirement for stem-loop I in vitro (Black et al. 1985; Krainer and Maniatis 1985), it is possible that other elements of U2 snRNP structure are perturbed by this method.

Yeast splicing extracts depleted of $\mathrm{U} 2$ can be complemented with synthetic U2 RNA lacking both stemloops III and IV (McPheeters et al. 1989). Taken together with our results on the conserved stem-loop C (IIb) and the $B^{\prime}$ sequence (Figs. 2 and 3), the only elements indispensable for splicing are the Sm site (Hamm et al. 1989; Pan and Prives 1989), which is essential for snRNP assembly and nuclear transport (for review, see Mattaj 
1988), the branchpoint recognition region (Parker et al. 1987), and stem-loop IIa (this work, Figs. 2 and 4).

Assuming that deletion of stem-loop IV abolishes association of the U2-specific proteins $\mathrm{A}^{\prime}$ and $\mathrm{B}^{\prime \prime}$ with $\mathrm{U} 2$ RNA (Hamm et al. 1989), the only U2-specific essential features of the U2 snRNP identified so far are the branchpoint complementary region and stem-loop IIa. Stem-loop IIa is not required to bind the $\mathrm{A}^{\prime}$ and $\mathrm{B}^{\prime \prime}$ proteins, because a deletion of Xenopus U2 including all of stem-loop IIa is assembled into a snRNP immune-precipitable by anti-Sm, anti- $\mathrm{A}^{\prime}$ or anti- $\mathrm{B}^{\prime \prime}$ antibodies (Hamm et al. 1989). The Sm site is essential for snRNP assembly and nuclear transport (see Mattaj 1988); however, this region is shared by a family of U-snRNAs and is not unique to the $U 2$ snRNP. Because tight binding of the only known intrinsic U2-specific snRNP proteins is dispensable for splicing (Hamm et al. 1989), the only U2-specific elements of the U2 snRNP available for essential interactions with other splicing factors are the RNA of the branchpoint interaction region and stemloop IIa. The branchpoint recognition region pairs with the pre-mRNA branchpoint at some time during splicing and contributes to the specificity of branchpoint selection in mammalian cells and yeast (Parker et al. 1987; Wu and Manley 1989; Zhuang and Weiner 1989|, although this does not exclude other roles.

\section{What is the role of stem-loop IIa in U2 function?}

The remaining U2-specific element, stem-loop IIa (positions 48-67), is an excellent candidate for a U2 snRNP structure that might interact with factors that either assemble the U2 snRNP with the pre-mRNA /Ruskin et al. 1988; Garcia-Blanco et al. 1989; Kramer 1989; Zamore and Green 1989) or with other components of the spliceosome. Because stem-loop IIa of U2 is conserved from mammals to trypanosomes, we expect it to have a conserved function in both cis- and trans-splicing. Branchpoint selection in yeast and mammalian cells appears to differ and is only beginning to be understood in trypanosomes (see introductory section); hence, any proposal for the function of the stem-loop in this process will need to account for these differences. Stem-loop IIa is not essential for snRNP assembly, as assayed by Sm protein binding or binding of U2-specific proteins $\mathrm{A}^{\prime}$ and $\mathrm{B}^{\prime \prime}$ in Xenopus (Hamm et al. 1989), and our observation that mutations in this region do not grossly destabilize U2 RNA in vivo would suggest that this might also be true in yeast. Mutations that disrupt the Sm site of yeast U5 and prevent snRNP protein binding tend to cause poor accumulation of U5 (Jones and Guthrie 1990), and we have seen no evidence of anything similar in any of our stem-loop IIa mutations (Figs. $2 \mathrm{c}$ and $4 \mathrm{~d}$ ).

Mammalian systems require auxiliary factors that interact with the pre-mRNA via the polypyrimidine region prior to or concomitant with U2 snRNP binding (Ruskin et al. 1988; Garcia-Blanco et al. 1989; Kramer 1989; Zamore and Green 1989). A weak, branchpoint sequencespecific, U2AF-independent binding of U2 snRNPs to branchpoint sequences can be detected (Nelson and
Green 1989|; and although this binding could be an intrinsic property of the U2 snRNP itself, the possibility of a second factor that contributes to binding of the U2 snRNP to branchpoint sequences in mammalian cells cannot be excluded (Nelson and Green 1989). In yeast, the presence of auxiliary factors is deduced by premRNA commitment studies using extracts depleted of U2 (Legrain et al. 1988; Ruby and Abelson 1988; Seraphin and Rosbash 1989). Transcripts lacking the UACUAAC sequence are poor competitors for a factor required to form a commitment complex on a wild-type transcript in the absence of U2 (Seraphin and Rosbash 1989). Although yeast introns do not always contain an obvious polypyrimidine stretch (Parker and Patterson 1987), a simple reconciliation of the data might be that functional equivalents of the mammalian factors in yeast recognize UACUAAC instead of polypyrimidine. In any case, as the only U2-specific structural element besides the branchpoint interaction region, stem-loop IIa may represent the part of $\mathrm{U} 2$ recognized by a common, conserved extrinsic factor that influences branchpoint selection or U2 snRNP binding to premRNA. As such, this region of $U 2$ could be a target for the regulation of splicing.

The proximity of stem-loop IIa to the branchpoint interaction region and its conserved nature also suggests that it could be involved in a conserved step of splicing after spliceosome assembly. This region could participate in the splicing reactions either indirectly as a binding site for catalytic factors with roles in the later steps of splicing or, possibly, as part of a catalytic element itself.

What is the functional contribution of phylogenetically conserved but dispensable RNA structures?

Dispensable U2 sequences do not have an essential role in the splicing reactions, but if conservation implies important function, the finding that several phylogenetically conserved U2 RNA structures are dispensable for viability may seem disturbing. In wild-type yeast, U2 function may not be growth rate limiting; hence, mutations lacking a detectable phenotype could still be reduced in function. Mutations scored as nonlethal, that is, those that disrupt stem-loop IIb or the conserved B-B' complementarity, could cause defects in a step of snRNP biogenesis or metabolism required under conditions other than those we have tested. The dispensable structures could also contribute to function in a manner not measurable in the laboratory but that may manifest itself only after many generations.

Xenopus U2 stem-loop IV is dispensable for splicing even though it is required for binding the U2-specific snRNP proteins $A^{\prime}$ and $B,{ }^{\prime \prime}$ suggesting that tight binding of these proteins is dispensable for splicing (Hamm et al. 1989). Certain ribosomal protein genes of Escherichia coli can be deleted without affecting viability, indicating that their binding to rRNA is dispensable for translation (Dabbs 1985). Phylogenetic conservation of certain elements of rRNA is very broad but clearly not essential for 
translation because organisms that lack them exist (Woese et al. 1983). A likely function for dispensable RNA elements and dispensable RNA-protein interactions may be to adjust the relative rates of competing, but distinct, RNA folding pathways, most of which would render the folded RNA nonfunctional. RNA and RNP stability could also be affected. In cases such as yeast U2, where the activity or steady-state level of the RNA can be reduced without catastrophic effects, the requirement for efficient RNA folding pathways or high abundance of the RNA or RNP may not be stringent enough to reduce the growth rate upon mutation.

Conservation of RNA sequences and structures may also arise by a "lesser evil" mechanism. This idea holds that certain highly conserved structures have no function themselves but are maintained because they are compatible with the structure of adjacent RNA elements that have essential functions. Mutations in these elements usually function more poorly because alternative foldings can be generated that occlude or disrupt adjacent functional elements, as even a single-base change in RNA can generate a new set of unexpected complementarities. This may explain the high degree of conservation surrounding the branchpoint interaction region of $\mathrm{U} 2$ or the presence of seemingly nonessential stemloops adjacent to essential sequences. Conservation need not imply function in this case but may imply the failure of equally compatible variant sequences to arise by mutation and be fixed. These relic RNA elements would be conserved by default.

\section{Materials and methods}

\section{Oligonucleotide mutagenesis}

The 0.95-kb HindIII fragment of the yeast U2 gene (LSR1, Ares 1986; SNR20, Parker et al. 1987) was cloned in the appropriate orientation in M13mpl0 and grown in E. coli RZ1032 for mutagenesis according to Kunkel (1985). Typically, the mutagenic oligonucleotide was phosphorylated using ATP and polynucleotide kinase (NEB) and annealed to the uracil-containing single-stranded DNA. After extension with Klenow fragment (U.S. Biochemicals) in the presence of ligase (NEB) and ATP, DNA was transformed into JM101 and plaques were screened with kinase-labeled mutagenic oligonucleotide under conditions that discriminate between mutant and wild-type phage. Mutants were picked and sequenced to confirm that they carried only the appropriate mutations. Double mutants were made either by mutagenesis of one of the single mutants or by including both mutagenic oligonucleotides in the reaction, screening duplicate plaque lifts, and picking phage that carried both mutations. The $0.95-\mathrm{kb}$ HindIII fragment from each mutant was then cloned into YCpU2-3' (Igel and Ares 1988) to generate a plasmid carrying an intact mutant U2 gene, ARS1, CEN3, and the LEU2 marker.

The oligonucleotides used to make the mutations follow (parentheses indicate mixed positions):

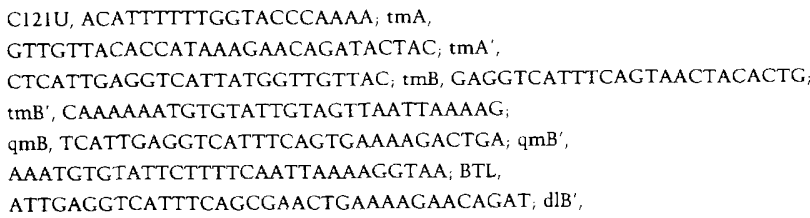

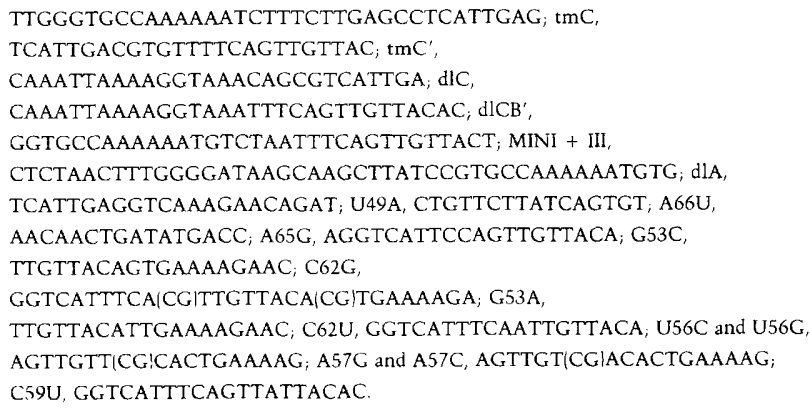

\section{Construction of plasmids and yeast strains}

Yeast strains were grown according to standard procedures (Sherman et al. 1986). Plasmid YCpLYS2-U2 was constructed by ligating the large EcoRI fragment of YCp631 containing the yeast LYS2 gene, the tetracycline-resistance gene from pBR322, a CEN3 fragment, and ARS1 (Barnes and Thorner 1986) to an EcoRI fragment containing pUC13 and a Sal-Sma fragment spanning the yeast U2 gene. YCpLYS2-U2C121U was constructed by replacing the small ClaI fragment of YCpLYS2-U2 encompassing positions -70 to 430 of the $U 2$ gene with the corresponding fragment from the U2 C121U mutant.

Strain MA70 was constructed beginning with MA2c1B (Igel and Ares 1988), which is MATa, leu2-3,112, ura3-52, his4-619, snr20::URA3 and carries the U2dlBD minigene on a LEU2 centromere plasmid. Spontaneous lys2- mutants were selected by plating on $\alpha$-AA (Chattoo et al. 1979) and were tested for spontaneous reversion and complementation of lysine auxotrophy by the LYS2 plasmid. One derivative with a stable lys2phenotype was transformed with the YCpLYS2-U2 plasmid. After growth in nonselective medium, cells were plated and tested to identify spontaneous mitotic segregants that had lost the mini-U2 plasmid with the LEU2 gene. One such segregant was called MA70 and is MATa, leu2-3,112, ura3-52, his4-619, snr20:: URA3, lys2 and carries the YCpLYS2-U2 plasmid. After testing the $\mathrm{C} 121 \mathrm{U}$ mutation by plasmid shuffling isee below) to ensure that it was not lethal, HI70 was constructed. HI70 is identical to MA70 except that it contains the YCpLYS2-U2C121U plasmid.

\section{Plasmid shuffling}

U2 mutations carried on the LEU2 plasmid were introduced into $\mathrm{HI} 70$ by transformation and selection for leucine independence. Cultures from single colonies were grown on synthetic complete medium lacking leucine and lysine and replicated onto medium containing $\alpha$-AA (Aldrich) as the primary nitrogen source (Chattoo et al. 1979). Replicates were incubated at $18,23,30$, and $36^{\circ} \mathrm{C}$ for $3-5$ days, and patches were scored for uniform growth. Viable U2 mutations allow growth of cells that spontaneously lose the YCpLYS2-U2 plasmid.

Strains carrying only the mutant $\mathrm{U} 2$ were isolated by restreaking on $\alpha-\mathrm{AA}$ at $30^{\circ} \mathrm{C}$ and were tested for temperature sensitivity by streaking on rich medium (YPD) or YPD plus $1 \mathrm{M}$ $\mathrm{KCl}$ (YPDK ; Tollervey and Guthrie 1985) at different temperatures and noting colony size after 3-6 days.

\section{Analysis of RNA}

RNA was isolated from yeast cultures $\left(50 \mathrm{ml}\right.$ at $\left.A_{600}=0.5-1.0\right)$ after collection by centrifugation and resuspension in $250 \mu \mathrm{l}$ of AK buffer (AK buffer is per $100 \mathrm{ml}$ : 1 gram triisopropylnapthalene, 6 grams sodium $p$-aminosalicylate, 1.17 gram sodium chloride, and $6 \mathrm{ml}$ water-saturated phenol, in water; Loening 1969). After addition of $0.5 \mathrm{ml}$ of $65^{\circ} \mathrm{C}$ phenol, cells were vor- 
texed for $30 \mathrm{sec}$ at high speed. The mixture was incubated for $30 \mathrm{~min}$ at $65^{\circ} \mathrm{C}$ and given a total of three additional 30 -sec vortexings at $10-\mathrm{min}$ intervals. The mixture was cooled on ice and spun for 5-10 min in a microcentrifuge. The aqueous phase was removed, and the phenol phase and interface were re-extracted by vortexing with $250 \mu \mathrm{l}$ of AK buffer. After centrifugation, the aqueous phases were pooled and extracted once with phenol/chloroform/isoamyl alcohol, $25: 24: 1$, once with chloroform and, after addition of sodium acetate $(\mathrm{pH} 5.2)$ to $0.3 \mathrm{M}$, were precipitated with ethanol, rinsed with $70 \%$ ethanol, dried, and resuspended in water. Yield is usually $1 \mathrm{mg}$ total RNA per $50 \mathrm{ml}$ cells at $A_{600}=1.0$.

In general, $10 \mu \mathrm{l}$ primer extension reactions were performed as follows: An appropriate amount of total RNA /usually 2-10 $\mu \mathrm{g}$ ) was incubated with $0.2 \mathrm{ng}$ of kinase-labeled primer in $6.5 \mu \mathrm{l}$ of water plus $0.5 \mu \mathrm{l}$ of $10 \times \mathrm{RT}$ buffer $(10 \times \mathrm{RT}$ buffer is $1.25 \mathrm{M}$ Tris-Cl, $175 \mathrm{mM} \mathrm{KCl}$ ) for $2 \mathrm{~min}$ at $65^{\circ} \mathrm{C}$ and then for $30 \mathrm{~min}$ at the appropriate temperature. Optimum annealing temperature was determined empirically for each primer. Samples were chilled on ice and $7 \mu \mathrm{l}$ of a cocktail containing (per reaction) 0.5 $\mu \mathrm{l}$ of $10 \times \mathrm{RT}$ buffer, $0.5 \mu \mathrm{l}$ of $0.1 \mathrm{M}$ dithiothreitol, $1 \mu \mathrm{l}$ of $0.1 \mathrm{M}$ magnesium chloride, $0.5 \mu \mathrm{l}$ of $2.5 \mathrm{~mm}$ each deoxynucleoside triphosphate, $0.25 \mu \mathrm{l} 1 \mathrm{mg} / \mathrm{ml}$ actinomycin $\mathrm{D}$, and $0.25 \mu \mathrm{l}$ of AMV reverse transcriptase (Life Sciences, 17-22 U/ $\mu$ l). Reactions were incubated at $42^{\circ} \mathrm{C}$ for $30-45 \mathrm{~min}$ and terminated by the addition of $5 \mu \mathrm{l}$ of a solution containing $30 \mathrm{mM}$ EDTA, 10 $\mu \mathrm{g} / \mathrm{ml} \mathrm{RNase} \mathrm{A}$, and $0.6 \mathrm{M}$ sodium acetate (pH 5.2). After incubation at $42^{\circ} \mathrm{C}$ for $5-10 \mathrm{~min}, 5 \mu \mathrm{l}$ of $0.2 \%$ SDS, $20 \mu \mathrm{g} / \mathrm{ml}$ proteinase $\mathrm{K}$, and $0.6 \mathrm{M}$ sodium acetate $(\mathrm{pH} 5.2)$ were added, and the incubation was continued at $65^{\circ} \mathrm{C}$ for $15 \mathrm{~min}$. The sample was ethanol-precipitated, dried, and suspended in $98 \%$ formamide and dyes for electrophoresis.

To measure the relative accumulation of the mutant U2 RNAs, HI70 transformed with the mutant plasmids was grown in synthetic complete medium lacking leucine and lysine (Sherman et al. 1986) Primer 23T (GTCTCTTCCCGTCCATTTTATTA) was annealed to $2.5 \mu \mathrm{g}$ of each RNA at $37^{\circ} \mathrm{C}$ and extended with reverse transcriptase as above except that 0.1 $\mathrm{mM}$ dideoxyadenosine triphosphate and no deoxyadenosine triphosphate was included. Products were fractionated on $7 \mathrm{M}$ urea/8\% polyacrylamide gels and autoradiographed.

To measure the accumulation of pre-U3 RNA in the mutants, an end-labeled 21-mer primer /CCAAGTTGGATTCAGTGGCTC) complementary to a region common to U3A and U3B (Hughes et al. 1987; Myslinski et al. 1990) was annealed to $2.5 \mu \mathrm{g}$ of total RNA at $58^{\circ} \mathrm{C}$ and extended with reverse transcriptase and all four deoxynucleoside triphosphates as above. Products were fractionated on $7 \mathrm{M}$ urea/6\% polyacrylamide gels and autoradiographed.

For blots, RNA was fractionated on $7 \mathrm{M}$ urea $/ 6 \%$ polyacrylamide gels and transferred electrophoretically to nylon membrane (Nytran, Schleicher \& Schuell) and probed with kinaselabeled oligo L15 (CAGATACTACACTTG) as described previously (Ares 1986).

\section{In vivo structure probing}

Cultures were grown in YEPD at $30^{\circ} \mathrm{C}$ to an $A_{600}$ of $0.5-1.0$. Ten milliliters of cells was incubated for 2 min with $200 \mu \mathrm{l}$ of a $1: 2$ dilution of DMS in $95 \%$ ethanol at $30^{\circ} \mathrm{C}$ with agitation. The reaction was quenched by addition of $5 \mathrm{ml}$ of ice-cold $0.7 \mathrm{M}$ 2-mercaptoethanol and $5 \mathrm{ml}$ of cold, water-saturated isoamyl alcohol, followed by vortexing and centrifugation in the cold. Cell pellets were washed once in $0.7 \mathrm{M} 2$-mercaptoethanol and pelleted, and the RNA was extracted as above. A "stop control" was performed to show that there is little or no modification of the RNA during the potentially denaturing RNA extraction and isolation procedure. In this case, cells were incubated identically, except that the DMS was added after the addition of the isoamyl alcohol.

Sites of DMS modification were mapped using reverse transcriptase and a labeled primer (Inoue and Cech 1985; Moazed et al. 1986). A 17-mer primer YSTR with $3^{\prime}$ end at position 117 within the Sm site (ATTATTTTGGGTGCCAA) was annealed to 5-10 $\mu \mathrm{g}$ of RNA and extended with all four deoxynucleoside triphosphates as above. For the sequencing lanes, four $10-\mu \mathrm{l}$ primer extension reactions were set up with unmodified RNA, and each was doped before the addition of the reverse transcriptase cocktail with $0.5 \mu \mathrm{l}$ of one of the following dideoxynucleoside triphosphate stocks: ddA, $0.75 \mathrm{mM}$; ddC, $1 \mathrm{~mm}$; ddG, 0.75 $\mathrm{mM}_{\text {; }} \mathrm{ddT}, 1.5 \mathrm{mM}$. Reverse transcription products were separated on $7 \mathrm{M}$ urea $/ 6 \%$ polyacrylamide gels, dried, and autoradiographed.

\section{Acknowledgments}

We thank Ted Powers, Gary Daubresse, and Vernita Ares for spur-of-the-moment oligonucleotide synthesis, Timothy Dreszer for construction of some mutants, and Mary Zavanelli for advice on in vivo structure probing. This work was supported by National Institutes of Health grant GM40478 and a Research Career Development Award to M.A.

The publication costs of this article were defrayed in part by payment of page charges. This article must therefore be hereby marked "advertisement" in accordance with 18 USC section 1734 solely to indicate this fact.

\section{References}

Ares, M., Jr. 1986. U2 RNA from yeast is unexpectedly large and contains homology to vertebrate U4, U5, and U6 small nuclear RNAs. Cell 47: 49-59.

Ares, M., Jr. and A.H. Igel. 1989. Phylogenetic comparison of U2 small nuclear RNA sequences suggests a pseudoknotted structure. UCLA Symp Mol. Cell. Biol. 94: 13-23.

Banroques, J. and J. Abelson. 1989. PRP4: A protein of the yeast U4/U6 small ribonucleoprotein particle. Mol. Cell. Biol. 9: 3710-3719.

Barnes, D. and J. Thorner. 1986. Genetic manipulation of Saccharomyces cerevisiae by use of the LYS2 gene. Mol. Cell. Biol. 6: 2828-2838.

Black, D., B. Chabot, and J.A. Steitz. 1985. U2 as well as U1 small nuclear ribonucleoproteins are involved in premessenger RNA splicing. Cell 42: 737-750.

Bindereif, A. and M. Green. 1987. An ordered pathway of snRNP binding during mammalian pre-mRNA splicing complex assembly. EMBO J. 6: 2415-2424.

Chabot, B. and J.A. Steitz. 1987. Multiple interactions between the splicing substrate and small nuclear ribonucleoproteins in spliceosomes. Mol. Cell. Biol. 7: 281-293.

Chattoo, B., F. Sherman, T. Fejellstedt, D. Menhnert, and M. Ogur. 1979. Selection of lys2 mutants of the yeast Saccharomyces cerevisiae by the utilization of $\alpha$-aminoadipate. $\mathrm{Ge}$ netics 93: 51-65.

Dabbs, E. 1985. Mutant studies on the prokaryotic ribosome. In Structure, function and genetics of ribosomes (ed. B. Hardesty and G. Kramer), pp. 733-748. Springer-Verlag, New York.

Garcia-Blanco, M., S. Jamison, and P. Sharp. 1989. Identification and purification of a 62,000 -dalton protein that binds specifically to the polypyrimidine tract of introns. Genes 
Dev. 3: $1874-1886$

Green, M. 1986. Pre-mRNA splicing. Annu. Rev. Genet. 20: $671-708$.

Guthrie, C. and B. Patterson. 1988. Spliceosomal snRNAs. Annu. Rev. Genet. 22: 387-419.

Hamm, J., N.A. Dathan, and I.W. Mattaj. 1989. Functional analysis of mutant Xenopus U2 snRNAs. Cell 59: 159-169.

Hannon, G., P. Maroney, J. Denker, and T. Nilsen. 1990. Transsplicing of nematode pre-messenger RNA in vitro. Cell 61: $1247-1255$.

Hartmuth, K. and A. Barta. 1988. Unusual branch point selection in processing of human growth hormone pre-mRNA. Mol. Cell. Biol. 8: 2011-2020.

Hughes, J., D. Konings, and G. Cesareni. 1987. The yeast homolog of U3 snRNA. EMBO /. 6: 2145-2155.

Igel, A.H. and M. Ares, Jr. 1988. Internal sequences that distinguish yeast from metazoan $\mathrm{U} 2$ are unnecessary for premRNA splicing. Nature 334: 450-453.

Inoue, T. and T. Cech. 1985. Secondary structure of the circular form of the Tetrahymena rRNA intervening sequence: A technique for RNA structure analysis using chemical probes and reverse transcriptase. Proc. Natl. Acad. Sci. 82: 648652.

Jones, M. and C. Guthrie. 1990. Unexpected flexibility in an evolutionarily conserved protein-RNA interaction: Genetic analysis of the $\mathrm{Sm}$ binding site. EMBO /. 9:2555-2561.

Keller, E. and W.A. Noon. 1985. Intron splicing: A conserved internal signal in introns of Drosophila pre-mRNAs. Nucleic Acids Res. 13: 4971-4981.

Konarska, M. and P. Sharp. 1986. Electrophoretic separation of complexes involved in the splicing of precursors to mRNAs. Cell 46: 845-855.

Krainer, A.R. and T. Maniatis. 1985. Multiple factors including the small nuclear ribonucleoproteins $U 1$ and $U 2$ are necessary for pre-mRNA splicing in vitro. Cell 42: 725-736.

Kramer, A. 1987. Analysis of RNaseA resistant regions of adenovirus 2 major late precursor-mRNA in splicing extracts reveals an ordered interaction of nuclear components with the substrate RNA. J. Mol. Biol. 196: 559-573.

. 1989. Presplicing complex formation requires two proteins and U2 snRNP. Genes Dev. 2: 1155-1167.

Kunkel, T. 1985. Rapid and efficient site-specific mutagenesis without phenotypic selection. Proc. Natl. Acad. Sci. 82: 488-492.

Laird, P. 1989. Trans-splicing in trypanosomes-Archaism or adaptation? Trends Genet. 5: 204-208.

Legrain, P., B. Seraphin, and M. Rosbash. 1988. Early commitment of yeast pre-mRNA to the spliceosome pathway. Mol. Cell. Biol. 8: $3755-3760$.

Loening, U. 1969. The determination of the molecular weight of ribonucleic acid by polyacrylamide gel electrophoresis: The effect of changes in conformation. Biochem. I. 113: $131-138$.

Mattaj, I. 1988. UsnRNP assembly and transport. In Structure and function of the major and minor small nuclear ribonucleoprotein particles (ed. M.L. Birnstiel), pp. 100-114. Springer-Verlag, Heidelberg.

McPheeters, D., P. Fabrizio, and J. Abelson. 1989. In vitro reconstitution of function yeast U2 snRNPs. Genes Dev. 3: 2124-2136.

Moazed, D., S. Stern, and H. Noller. 1986. Rapid chemical probing of conformation in $16 \mathrm{~S}$ ribosomal RNA and $30 \mathrm{~S}$ ribosomal subunits using primer extension. I. Mol. Biol. 187: 399-416.

Mottram, J., K. Perry, P. Lizardi, R. Luhrmann, N. Agabian, and N. Nelson. 1989. Isolation and sequence of four small nu- clear U RNA genes of Trypanosoma brucei subsp. brucei: Identification of U2, U4, and U6 analogs. Mol. Cell. Biol. 9: $1212-1223$.

Mount, S. 1982. A catalog of splice junction sequences. Nucleic Acids Res. 10: 459-472.

Myslinski, E., V. Segault, and C. Branlant. 1990. An intron in the genes for U3 small nucleolar RNAs of the yeast Saccharomyces cerevisiae. Science 247: 1213-1216.

Nelson, K. and M. Green. 1989. Mammalian U2 snRNP has a sequence-specific RNA-binding activity. Genes Dev. 3: $1562-1571$.

Nilsen, T. 1989. Trans-splicing in nematodes. Exp. Parasitol. 69: $413-416$

Pan, Z.-Q. and C. Prives. 1989. U2 snRNA sequences that bind U2-specific proteins are dispensable for the function of U2 snRNP in splicing. Genes Dev. 3: 1887-1898.

Parker, R. and B. Patterson. 1987. Architecture of fungal introns: Implications for spliceosome assembly. In Molecular biology of RNA: New perspectives (ed. M. Inouye and B. Dudock), pp. 133-149. Academic Press, San Diego.

Parker, R., P. Siliciano, and C. Guthrie. 1987. Recognition of the TACTAAC box during mRNA splicing in yeast involves base pairing to the U2-like snRNA. Cell 49: 229-239.

Patzelt, E., K. Perry, and N. Agabian. 1989. Mapping of branch sites in trans-spliced pre-mRNAs of Trypanosoma brucei. Mol. Cell. Biol. 9: 4191-4297.

Pleij, C., K. Reitveld, and L. Bosch. 1985. A new principal of RNA folding based on pseudoknotting. Nucleic Acids Res. 13: $1717-1731$

Reed, R. and T. Maniatis. 1988. The role of the mammalian branchpoint sequence in pre-mRNA splicing. Genes Dev. 2: $1268-1276$.

Ruby, S. and J. Abelson. 1988. An early hierarchic role of U1 small nuclear ribonucleoprotein in spliceosome assembly. Science 242: 1028-1035.

Ruskin, B., P. Zamore, and M. Green. 1988. A Factor, U2AF, is required for U2 snRNP binding and splicing complex assembly. Cell 52: 207-219.

Seraphin, B. and M. Rosbash. 1989. Identification of functional U1 snRNA-pre-mRNA complexes committed to spliceosome assembly and splicing. Cell 59: 349-358.

Sherman, F., G. Fink, and J. Hicks. 1986. Methods in yeast genetics. Cold Spring Harbor Laboratory, Cold Spring Harbor, New York.

Shuster, E.O. and C. Guthrie. 1988. Two conserved domains of yeast U2 snRNA are separated by 945 nonessential nucleotides. Cell 55: 41-48.

. 1990. Human U2 snRNA can function in pre-mRNA splicing in yeast. Nature 345: 270-273.

Smith, C., E. Porro, J. Patton, and B. Nadal-Ginard. 1989. Scanning from an independently specified branch point defines the $3^{\prime}$ splice site of mammalian introns. Nature 342 : $243-$ 247.

Steitz, J.A., D.L. Black, V. Gerke, K.A. Parker, A. Kramer, D. Frendewey, and W. Keller. 1988. Functions of the abundant U-snRNPs. In Structure and function of the major and minor small nuclear ribonucleoprotein particles (ed. M.L. Birnstiel), pp. 115-154. Springer-Verlag, Heidelberg.

Thomas, J., K. Lea, E. Zucker-Aprison, and T. Blumenthal. 1990. The spliceosomal snRNAs of Caenorhabditis elegans. Nucleic Acids Res. 18: 2633-2642.

Tollervey, D. and C. Guthrie. 1985. Deletion of a yeast small nuclear RNA gene impairs growth. EMBO J. 4: 3873-3878.

Tschudi, C. and E. Ullu. 1990. Destruction of U2, U4, or U6 small nuclear RNAs blocks trans-splicing in trypanosome cells. Cell 61: 456-459. 
Tschudi, C., F. Richards, and E. Ullu. 1986. The U2 analog of Trypanosoma brucei gambiense: Implications for a splicing mechanism in trypanosomes. Nucleic Acids Res. 14: 88938903.

Tschudi, C., S. Williams, and E. Ullu. 1990. Conserved sequences in the U2 snRNA genes of Kinetoplastida do not include the putative branchpoint recognition region. Gene 91: $71-77$.

Tuerk, C., P. Gauss, C. Thermes, D. Groebe, M. Gayle, N. Guild, G. Stormo, Y. D'Aubenton-Carafa, O. Uhlenbeck, I. Tinoco, E. Brody, and L. Gold. 1988. CUUCGG hairpins: Extraordinarily stable RNA secondary structures associated with various biochemical processes. Proc. Natl. Acad. Sci. 85: 1364-1368.

Woese, C., R. Gutell, R. Gupta, and H. Noller. 1983. Detailed analysis of the higher order structure of 16S-like ribosomal ribonucleic acid. Microbiol. Rev. 47: 621-669.

Woolford, J. 1989. Nuclear pre-mRNA splicing in yeast. Yeast 5: 439-457.

Wu, J. and J. Manley. 1989. Mammalian pre-mRNA branch site selection by $\mathrm{U} 2$ snRNP involves base pairing. Genes Dev. 3: $1553-1561$.

$\mathrm{Xu}$, Y., S. Petersen-Bjorn, and J. Friesen. 1990. The PRP4 (RNA4) protein of Saccharomyces cerevisiae is associated with the $5^{\prime}$ portion of the U4 small nuclear RNA. Mol. Cell. Biol. 10: 1217-1225.

Zamore, P. and M. Green. 1989. Identification, purification and biochemical characterization of $\mathrm{U} 2$ small nuclear ribonucleoprotein auxiliary factor. Proc. Natl. Acad. Sci. 86: 9243-9247.

Zhuang, Y. and A.M. Weiner. 1989. A compensatory base change in human U2 snRNA can suppress a branch site mutation. Genes Dev. 3: 1545-1552.

Zhuang, Y., A. Goldstein, and A. Weiner. 1989. UACUAAC is the preferred branch site for mammalian mRNA splicing. Proc. Natl. Acad. Sci. 86: 2752-2756. 


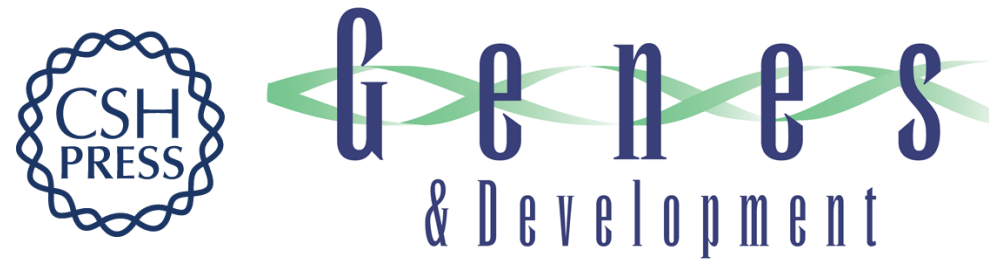

\section{Lethal and temperature-sensitive mutations and their suppressors identify an essential structural element in U2 small nuclear RNA.}

$\mathrm{M}$ Ares and $\mathrm{A} \mathrm{H}$ Igel

Genes Dev. 1990, 4:

Access the most recent version at doi:10.1101/gad.4.12a.2132

References This article cites 58 articles, 24 of which can be accessed free at:

http://genesdev.cshlp.org/content/4/12a/2132.full.html\#ref-list-1

License

Email Alerting

Service

Receive free email alerts when new articles cite this article - sign up in the box at the top right corner of the article or click here.

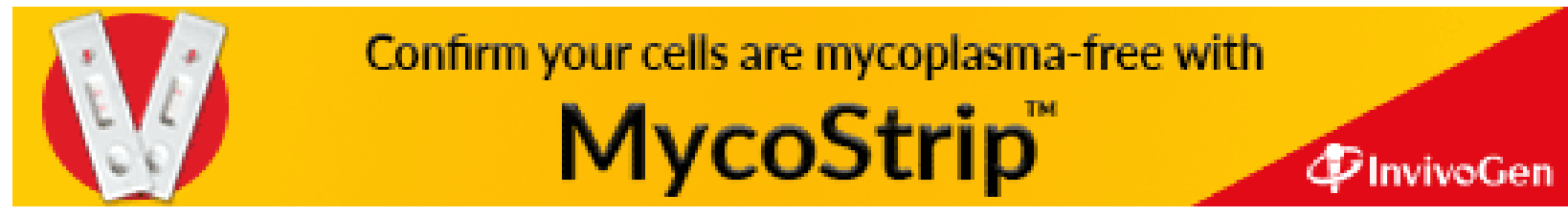

